Published as: Griffiths, M.D. \& Auer, M. (2015). Research funding in gambling studies: Some further observations. International Gambling Studies, 15, 15-19.

\title{
Research funding in gambling studies: Some further observations
}

All of us that work in the gambling studies field will have been interested in reading Cassidy's (2014) editorial on producing and publishing gambling research, and the response to it by the editors of this journal (i.e., Blaszczynski \& Gainsbury, 2014). Few people would disagree that the funding of research programmes in the gambling studies field (a) are often politically motivated, (b) are relatively short-term, and (c) need to be viable, sustained, and long-term (Griffiths, 2009b). Furthermore, debates concerning funding and potential conflicts of interest are not new and a number of us in the field have provided our observations on the topic previously including the first author (see Griffiths, 2009a; 2009b). This brief commentary picks up on some of the issues raised by both Cassidy (2014) and Blaszczynski and Gainsbury (2014).

The first issue we would like to raise is whether there is any fundamental difference between research funded by the gambling industry and consultancy funded by the gambling industry. Cassidy's editorial implicitly appears to support the notion that any money that any academic (or their university or company) receives from the gambling industry (directly or indirectly) is inherently bad and likely to affect how academics report their research findings. To us, research and consultancy are two very separate activities (although it could be argued that in some instances, the line is beginning to blur). Broadly speaking, and based on our own experience, research is typically carried out with the aim of disseminating the findings in the public domain. Consultancy is typically carried out with the aim of keeping the findings within the organization that commissioned the consultancy work and out of the public domain. Although there are exceptions to this, the real issue is whether doing consultancy with the gambling industry in any way impacts on independently funded and subsequently published gambling research.

The relationship between academics and the gambling industry has changed greatly over the last decade or so. During the 1980s and 1990s, any academic that was carrying out research into problem gambling was often perceived as 'anti-gambling' by many in the gambling industry. However, neither of us are 'anti-gambling' in the slightest. In the 2000s, social responsibility in gambling became a major issue - particularly when the 
granting of operating licenses became contingent on gambling companies demonstrating to their regulators what they were doing in terms of player protection and harm minimization. Within a few years, gambling companies all over the world began seeking the advice of academics (including those they had previously shunned) wanting to know how they can make their business more socially responsible. Many gambling companies started to develop the same underlying philosophy as academics and embed social responsibility practices throughout their busness models (e.g., Svenska Spel, Norsk Tipping, Nova Scotia Gaming Corporation, Camelot, British Columbia Lotttery Corporation, Atlantic Lottery Corporation, Casinos Austria, Holland Casino, Loto Quebec, etc.). The shared vision was to minimize problem gambling. Both of us carry out consultancy with the gaming industry in the area of social responsibility, responsible gambling, harm minimization, and player protection. We believe the gambling industry can benefit from our expertise and that there is nothing morally wrong in what we do. To us, this is totally separate from research activity.

Our second issue concerns the benefits of working collaboratively with the gambling industry. One of the key reasons for working together with the gaming companies is because they give researchers access to their customer base of confirmed gamblers. As noted by Blaszczynski and Gainsbury (2014), one of the major problems with research in the field is that much of the published research is not actually carried out on gamblers (with much experimental and survey research being carried out with convenience samples of psychology undergraduates). Many of us in the field have said for many years that academics need to start working in co-operation with gaming companies (Griffiths, 2009b) to produce work that will move the field forward, and not repeating the same kind of research over and over again.

More recently, we were given access to large datasets of gamblers by a number of different gambling companies and have started to use their behavioural tracking data we were given to (a) develop new parameters for assessing gaming intensity such as our work on 'theoretical loss' (e.g., Auer \& Griffiths, 2014a; 2014b; Auer, Schneeberger \& Griffiths, 2012), and (b) assess the impact of social responsibility features (e.g., time and money spending limits, pop-up messages) with real gamblers, in real time, on real gambling sites (e.g., Auer \& Griffiths, 2013; Auer, Malischnig \& Griffiths, 2014). The bottom line is that we would never have been able to undertake this kind of innovative 
research with participant sizes of hundreds of thousands of real gamblers without working in co-operation with the gambling industry. (It should also be noted that the gambling companies in question did not fund the research but provided simply provided access to their databases and customers). In fact, we would go as far as to say the research would have been impossible without gambling industry co-operation. Data access provided by the gambling industry has to be one of the key ways forward if the field is to progress.

Unlike other consumptive and potentially addictive behaviours (smoking cigarettes, drinking alcohol, etc.), researchers can study real-time gambling (and other potentially addictive behaviours like video gaming and social networking [Griffiths, Kuss \& Demetrovics, 2014]) in a way that just cannot be done in other chemical and behavioural addictions (e.g., sex, exercise, work, etc.) because of online and/or card-based technologies. There is no equalivalent of this is the tobacco or alcohol industry, and is one of the reasons why researchers in the gambling field are beginning to liaise and/or collaborate with gambling operators. As researchers, we should always strive to improve our theories and models and it appears strange to neglect this purely objective information simply because it involves working together with the gambling industry. This is especially important given the recent research by Braverman, Tom and Shaffer (2014) using data from gamblers on the bwin website showing that self-recollected information does not match with objective behavioural tracking data.

Our third issue is where to draw the line between doing something that could be perceived by others (both inside and outside the gambling field) as the gambling industry having an influence on what we do. For instance, Cassidy (2014) noted a number of competing interests could include companies paying for individuals to speak or attend conferences, or being paid by a company to run training sessions. We have done both of these types of activity but would argue that neither of these are influenced at all by a gambling company (at least in our own cases). Most major academic gambling conferences are sponsored directly (or indirectly) by gambling companies. If an invited speaker is provided with a business class flight that has at least in part (or in full) been paid by the gambling industry, does that really have any influence on that person's publsihed research? Ironically, one of us [MDG] was one of the interviewees for Cassidy's study and was interviewed during the breakfast session of a major conference 
that was heavily sponsored by the gambling industry. Was Cassidy herself at all influenced by the fact she was attending a conference subsidized (in part) by many international gambling companies? We do not think that she was, so does that mean there are some things that academics do (that rely on gambling industry funding) but do not interfere with the the independence of their published research?

Our fourth point concerns the publishing of multi-author research papers where some of the authors may have worked directly with a gaming company while others did not. For instance, the Editor-in-Chief of this journal [Alex Blaszczynski] and one of us [MDG] both recently contributed to a paper with our Norwegian colleagues at the University of Bergen on the relationship between structural game characteristics on slot machines and subsequent gambling behaviour (i.e., Leino, Torsheim, Blaszczynski, Griffiths, Mentzoni, Pallesen \& Molde, 2014). The study utilized behavioural tracking data from the player cards of over 31,000 Norwegian slot machine players. The Norwegian researchers were provided with access to the data by the Norwegian gambling company Norsk Tipping. However, neither Blaszczynski or Griffiths had any personal contact with the gambling industry and merely provided intellectual input into the final published paper. Would this be a case where Cassidy thinks our intellectual views are compromised given the paper involved some of the authors working together with the gambling industry (and even though two of the authors had no liaison with the collaborating partners [i.e., Nork Tipping] at all during the duration of the project)?

Another crucial issue that Blaszczynski and Gainsbuty (2014) raised concerns the personal ideological, philosophical and/or religious beliefs. We would argue that it is these beliefs that are more likely to influence how results are written up and disseminated rather than any other factor (such as who funded the research). For instance, here is a hypothetical example of the same finding being reported in a number of different ways applied to a country with a population about the size of the UK (64 million people):

(1) "The overwhelming majority of the sample surveyed (99\%) had no gambling problem"

(2) "Only a tiny minority of the sample surveyed (1\%) had a gambling problem"

(3) "99\% of the sample surveyed had no gambling problems"

(4) "1\% of the sample of the sample surveyed had a gambling problem" 
(5) "Findings from the survey indicate that approximately one million adults have a gambling problem"

Depending on whether a researcher is pro-gambling, gambling-neutral, or anti-gambling, the hypothetical examples could provide different ways in which to write up exactly the same finding. These far more subtle ways of presenting data may provide clues to a person's ideological standpoint on gambling but they are a lot harder to prove than whether somebody received gambling funding.

Blaszczynski and Gainsbury (2014) also note that Government may also play a role in what research gets funded in the first place and that the boundary between government and industry is often blurred. We would also add, that research that is actually funded by Government bodies and agencies often have their own agendas and want results of their 'independent' research reported in particular ways and ask report authors to disseminate findings with specific emphases so that they are 'on message' with what the Government department wants to get across to varying stakeholder groups. It is our experience (in relation to writing consultancy reports rather than research reportds) that it is work commissioned by Government agencies that receive far more scrutiny and criticism than those funded by the gambling industry. Furthmore, we should not lose sight of the fact that any funder of any research project can (and often does) have input into the final report or subsequent publications. A charity that campaigns on behalf of the homeless and puts out a tender for a literature review on the realtionship between homelessness and problem gambling, or a debt counselling agency that commissions research on the relationship between gambling and poverty, will always have their own agendas and want research being written up that will help their cause and mission (even if it is in the form of a gentle steer in a particular direction rather than something more blatant).

Finally, when it comes to funding for gambling research there is always going to be tension between an 'ideal world' philosophy and 'real world' pragmatism. Due to the current economic climate worldwide, public funding for all scientific research has decreased and university academics are under increasing pressure to seek funding from the private sector (something that Cassidy notes in her editorial). Bringing in money is now written into our job descriptions, and partnerships between academia and business are not only desired but expected. Clearly, some countries are much better funded for 
gambling research than others depending on the funding mechanisms and funding streams available. For instance, provinces across Canada appear to have particularly well developed funding streams compared to many other countries. Personally, we would prefer to see statutory levy in place so that a small proportion of money raised from all gambling operators' profits are channelled into an indepenent charitable trust that then distributes fairly in the areas of education/prevention, treatment, and research. However, this alone would be unlikely to prevent industry-sponsored research but it should translate to more and better 'independent' research being carried out in the gambling studies field.

\section{References}

Auer, M., \& Griffiths, M. D. (2013). Limit setting and player choice in most intense online gamblers: An empirical study of online gambling behaviour. Journal of Gambling Studies, 29, 647-660.

Auer, M., \& Griffiths, M. D. (2014a). Personalised feedback in the promotion of responsible gambling: A brief overview. Responsible Gambling Review, 1, 27-36.

Auer, M., \& Griffiths, M. D. (2014b). An empirical investigation of theoretical loss and gambling intensity. Journal of Gambling Studies, 30, 879-887.

Auer, M., \& Griffiths, M. D. (2014c). Theoretical loss and gambling intensity (revisited): A response to Braverman et al (2013). Journal of Gambling Studies, DOI 10.1007/s10899014-9463-4

Auer, M., Malischnig, D., \& Griffiths, M. D. (2014). Is 'pop-up' messaging in online slot machine gambling effective? An empirical research note. Journal of Gambling Issues, 29, 1 10.

Auer, M., Schneeberger, A., \& Griffiths, M. D. (2012). Theoretical loss and gambling intensity: A simulation study. Gaming Law Review and Economics, 16, 269-273.

Blaszczynski, A., \& Gainsbury, S. (2014). Editor's notes. International Gambling Studies. 
DOI: $10.1080 / 14459795.2014 .971585$

Braverman, J., Tom, M., \& Shaffer, H. J. (2014). Accuracy of self-reported versus actual online gambling wins and losses. Psychological Assessment, 26, 865-877.

Cassidy, R. (2014). Fair game? Producing and publishing gambling research. International Gambling Studies, DOI: 10.1080/14459795.2014.971420

Griffiths, M. D. (2009a). Minimising harm from gambling: What is the gambling industry's role? Addiction, 104, 696-697.

Griffiths, M. D. (2009b). Gambling research and the search for a sustainable funding infrastructure. Gambling Research, 21(1), 28-32.

Griffiths, M. D., Kuss, D.J., \& Demetrovics, Z. (2014). Social networking addiction: An overview of preliminary findings. In K. Rosenberg \& L. Feder (Eds.), Behavioral Addictions: Criteria, Evidence and Treatment (pp.119-141). New York: Elsevier.

Griffiths, M. D., Wood, R. T. A., \& Parke, J. (2009). Social responsibility tools in online gambling: A survey of attitudes and behaviour among Internet gamblers. CyberPsychology and Behavior, 12, 413-421.

Leino, T., Torsheim, T., Blaszczynski, A., Griffiths, M. D., Mentzoni, R., Pallesen, S., \& Molde, H. (2014). The relationship between structural characteristics and gambling behavior: A population based study. Journal of Gambling Studies, DOI 10.1007/s10899014-9477-y

Wood, R. T. A., Shorter, G. W., \& Griffiths, M. D. (2014). Rating the suitability of responsible gambling features for specific game types: A resource for optimizing responsible gambling strategy. International Journal of Mental Health and Addiction, 12, 94 112. 